\title{
Blood pressure values and depression in hypertensive individuals at high cardiovascular risk
}

\author{
Cilia Mejia-Lancheros ${ }^{1}$, Ramón Estruch ${ }^{2,3,4}$, Miguel Angel Martínez-González ${ }^{3,5}$, Jordi Salas-Salvadó2,3,6, \\ Dolores Corella 2,3,7, Enrique Gómez-Gracia, ${ }^{3,8}$, Miquel Fiol 2,9, José Manuel Santos 2,10, Montse Fitó 2,11, \\ Fernando Arós ${ }^{3,12}$, Lluis Serra-Majem ${ }^{3,13}$, Xavier Pintó ${ }^{3,14}$, Josep Basora ${ }^{2,3,15}$, José Vicente Sorlí, 2,3,76, \\ Miguel-Angel Muñoz ${ }^{1,17^{*}}$ and for the PREDIMED Study Investigators
}

\begin{abstract}
Background: Hypertension and depression are both important risk factors for cardiovascular diseases. Nevertheless, the association of blood pressure on and depression has not been completely established. This study aims to analyze whether depression may influence the control of blood pressure in hypertensive individuals at high cardiovascular risk.

Methods: Cross-sectional study, embedded within the PREDIMED clinical trial, of 5954 hypertensive patients with high cardiovascular risk factor profiles. The relationship between blood pressure control and depression was analyzed. A multivariate analysis (logistic and log-linear regression), adjusting for potential confounders (socio-demographic factors, body mass index, lifestyle, diabetes, dyslipidemia, and antihypertensive treatment), was performed.

Results: Depressive patients, with and without antidepressant treatment, had better blood pressure control (OR: 1.28, Cl 95\%: 1.06-1.55, and OR: 1.30, Cl 95\%: 1.03-1.65, respectively) than non-depressive ones. Regarding blood pressure levels, systolic blood pressure values $(\mathrm{mmHg})$ were found to be lower in both treated and untreated depressive patients (Log coefficient Beta: $-1.59,95 \% \mathrm{Cl}:-0.50$ to -2.69 and Log coefficient Beta: -3.49 , $95 \% \mathrm{Cl}:-2.10$ to -4.87 , respectively).
\end{abstract}

Conclusions: Among hypertensive patients at high cardiovascular risk, the control of blood pressure was better in those diagnosed with depression.

Trial registration: Unique identifier: ISRCTN35739639.

Keywords: Hypertension, Depression, Blood pressure

\section{Background}

High blood pressure is a key risk factor for cardiovascular disease (CVD) incidence [1-3]. Its prevalence is globally estimated to be around $40 \%$, and it accounted for approximately 7.5 million deaths in 2008 [1]. The latest health statistics from the United States of America have reported a hypertension prevalence of 33\% among adults, and within this population only $53 \%$ reached target levels recommended by guidelines [4]. In addition to

\footnotetext{
*Correspondence: mamunoz.bcn.ics@gencat.cat

${ }^{1}$ Department of Paediatrics, Obstetrics, Gynaecology and Preventive

Medicine, Universitat Autònoma de Barcelona, Barcelona, Spain

${ }^{17}$ Catalan Institute of Health, Institut d'Investigació en Atenció Primària Jordi

Gol, Sardenya 375,Entlo, 08025 Barcelona, Spain

Full list of author information is available at the end of the article
}

the classical risk factors, in the last decade the impact of psychosocial determinants, such as educational level and depression, has received increasing attention [5-7]. The prevalence of depression has risen dramatically in recent years; in fact, the World Health Organization (2012) reported more than 350 million people suffering from this condition worldwide [8]. Depression has been found to coexist with CVD and its associated risk factors such as hypertension, diabetes, overweight, and unhealthy life styles (smoking and harmful alcohol consumption) $[7,9,10]$. Evidence supporting the relationship between depression and blood pressure (BP) is however, complex and remains controversial [11-13]. In addition, evidence addressing the relationship between depression and hypertension control in hypertensive populations with 
respect to the control of hypertension are scarce. The optimal control of BP is an essential key to reduce the risk level of cardiovascular diseases [3]. Since depression is an additional cardiovascular risk factor as some antidepressant medication may modify BP levels. The present study was, therefore, aimed at determining the association of depression and BP control in elderly hypertensive people at high cardiovascular risk.

\section{Methods}

\section{Study design and participants}

Cross-sectional study using baseline data of hypertensive participants at high cardiovascular risk from the PREDIMED Study (Prevention with the Mediterranean diet). All details of the PREDIMED study including enrollment, design, population, methods, and main results have been described elsewhere $[14,15]$. For the present work, all the hypertensive individuals $(\mathrm{N}=5954)$ from the 7447 PREDIMED study participants were included. They fulfilled at least 1 of the 2 following criteria: 1$)$ men (55-80 years old) and women (60-80 years old) with either type-2 diabetes or 2) three or more CVD risk factors (current smoking, dyslipidemia, body mass index $(\mathrm{BMI})>=25 \mathrm{~kg} / \mathrm{m} 2$, or family history of premature cardiovascular diseases). Exclusion criteria included previous history of CVD or other diseases such as food allergies, alcoholism, infection or acute inflammation, physical or mental disability, and those individuals taking part in any other clinical trial. Participants' data were collected from medical records, clinical evaluation, and face to face interviews. Validated questionnaires were administered in order to obtain data on nutritional and physical activity habits [16-18]. Blood samples for laboratory tests were also obtained. Details on collection and measurements have been published elsewhere $[13,14]$.

\section{Ethical considerations}

All participants signed an informed consent. The project was conducted in accordance with the Declaration of Helsinki and its subsequent amendments. The PREDIMED study was approved by the Institutional Review Board of Hospital Clinic (Barcelona, Spain), and registered in the Current Controlled Trials (number: ISRCTN3573963, http://www.controlled-trials.com/ISRCTN35739639).

\section{End points}

\section{Control of blood pressure}

BP was considered well-controlled when systolic and diastolic blood pressure values (SBP, DBP) were below $140 \mathrm{mmHg}$ and $90 \mathrm{mmHg}$, respectively, according to the recommendations of the European guidelines on cardiovascular disease prevention in clinical practice [18]. Both SBP and DBP were calculated based on the average of 4 measurements (two in the right arm and two in the left), taken in the primary care centers by well-trained primary care nurses. BP measures were assessed after a suitable resting period (more than 5 minutes) in a sitting position to avoid variability in the values due to patient movement/displacement. For the measurement of BP, a validated semiautomatic sphygmomanometer (Omron HEM-705CP) with an appropriately sized cuff for the arm of each participant was used. The determinations were performed at two minute intervals. The mean of the second and third measurement was recorded. When a difference $>5 \mathrm{~mm} \mathrm{Hg}$ between the two determinations more than $5 \mathrm{~mm} \mathrm{Hg}$ was detected the whole process was repeated.

\section{Main independent variable Depression}

Diagnosis of depression was established at the visit of inclusion in the study, by face to face interview, and the information was further confirmed in the clinical records. Participants were asked if some doctor had previously diagnosed them from depression. In Spain, the diagnosis of depression is carried out both by psychiatrists and family doctors. Usually, diagnostic is made following the American Psychological Association clinical criteria (DSM-IV) and those of the International Classification of Diseases (ICD) related to Mental and Behavioral Disorders or other mental health scales, included in the standardized health guidelines from the Spanish Ministry of Health. Antidepressant treatment was registered according to the patients' self-reported information and consulting at the clinical records. In addition, participants were also asked whether they had taken any antidepressants in the previous month. They were finally classified as: no diagnosis of depression (no previous diagnosis of depression and not taking antidepressants), untreated depression (diagnosis of depression and not taking any antidepressants), and treated depression (diagnosis of depression and taking at least one of the following: selective serotonin reuptake inhibitors, non-selective monoamine reuptake inhibitors, monoamine oxidase A inhibitors, antidepressants in combination with psycholeptics, and other antidepressant agents). Participants were also asked about the time that had elapsed from since their first diagnosis of depression which was categorized as: $\leq 5$ years, $6-10$ years, and $\geq 11$ years.

\section{Co-variables}

The following co-variables were taken into consideration: age, sex, anxiolytic or sedative treatment, comorbidity (diabetes and dyslipidemia), and antihypertensive treatment (angiotensin-converting-enzyme inhibitor (ACE inhibitors), diuretics, calcium channel blockers, angiotensin II receptor antagonists, $\beta$-blockers, $\alpha$-blockers, or other antihypertensive drugs). 


\section{Potential confounding variables}

Educational attainment, BMI, smoking habits, adherence to the Mediterranean diet pattern, physical activity, and alcohol intake were included in the analysis as they can be correlated with both depression and BP control.

\section{Statistical analysis}

The descriptive analysis of categorical variables was expressed as percentages and quantitative variables by mean and standard deviation (SD). Bivariate analyses included chi square tests and ANOVA F-test. A multivariate logistic model was fitted to evaluate the association and estimate Odds Ratio (OR) between depression level and length, and good BP control of blood pressure. To confirm the association observed between well-controlled BP and depression, continuous variables were adjusted by loglinear regression for potential confounders (age, sex, educational attainment, anxyolitic or sedative treatment, BMI, lifestyle, hypertension co-morbidity, and antihypertensive treatment). Those statistically significant at bivariate analysis, or which could have any clinical relationship with the final end-points, were included in the multivariate

Table 1 Main characteristics of study population by depression and depression length

\begin{tabular}{|c|c|c|c|c|c|c|c|c|}
\hline \multirow[b]{4}{*}{ Characteristics of participants } & \multicolumn{4}{|c|}{ Depression levels } & \multicolumn{4}{|c|}{ Time with depression diagnostic } \\
\hline & \multirow{2}{*}{$\begin{array}{l}\text { No depression } \\
\qquad(\mathrm{N}=5027)\end{array}$} & \multirow{2}{*}{$\begin{array}{l}\text { Untreated } \\
\text { depression } \\
(\mathrm{N}=569)\end{array}$} & \multirow{2}{*}{$\begin{array}{c}\text { Treated } \\
\text { depression }^{\mathrm{a}} \\
(\mathrm{N}=358)\end{array}$} & \multirow[b]{3}{*}{ P-value } & \multirow{2}{*}{$\begin{array}{l}\leq 5 \text { years } \\
(N=268)\end{array}$} & \multirow{3}{*}{$\begin{array}{c}\text { 6-10 years } \\
(\mathrm{N}=159) \\
\%\end{array}$} & \multirow{3}{*}{$\begin{array}{c}\geq 11 \text { years } \\
(\mathrm{N}=500) \\
\text { P-value }\end{array}$} & \multirow[b]{3}{*}{ P-value } \\
\hline & & & & & & & & \\
\hline & $\%$ & $\%$ & $\%$ & & & & & \\
\hline Age (years) ${ }^{\dagger}$ & $67.3(6.2)$ & $66.9(6.0)$ & $66.8(5.7)$ & 0.137 & $66.4(6.0)$ & $66.7(6.1)$ & $67.1(5.8)$ & 0.290 \\
\hline Sex (Women) & 56.0 & 79.8 & 84.6 & 0.001 & 82.5 & 78.0 & 82.4 & 0.881 \\
\hline \multicolumn{9}{|l|}{ Educational attainment } \\
\hline High level & 7.6 & 4.9 & 6.4 & 0.003 & 7.1 & 7.5 & 4.0 & 0.280 \\
\hline Middle level & 15.9 & 13.7 & 11.7 & & 11.6 & 12.6 & 13.8 & \\
\hline Low level & 76.6 & 81.4 & 81.8 & & 81.3 & 79.9 & 82.2 & \\
\hline Antidepressant treatment ${ }^{\mathrm{a}}$ & - & - & - & - & 45.9 & 37.7 & 35.0 & 0.004 \\
\hline Antianxiety or sedative treatment ${ }^{b}$ & 14.8 & 37.8 & $61.5)$ & 0.001 & 45.5 & 48.4 & 47.2 & 0.700 \\
\hline Body Mass Index $\left(\mathrm{Kg} / \mathrm{m}^{2}\right)^{\dagger}$ & $30.1(3.8)$ & $30.8(4.2)$ & $30.5(3.6)$ & 0.001 & $30.5(4.0)$ & $30.8(3.8)$ & $30.8(4.0)$ & 0.521 \\
\hline \multicolumn{9}{|l|}{ Life styles } \\
\hline Smoking $^{c}$ & 38.3 & 24.6 & 23.5 & 0.001 & 22.8 & 24.5 & 24.8 & 0.543 \\
\hline Low adherence to the MeDiet pattern ${ }^{d}$ & 45.8 & 48.0 & 50.8 & 0.042 & 47.4 & 45.3 & 51.2 & 0.256 \\
\hline Sedentary ${ }^{\mathrm{e}}$ & 35.0 & 44.6 & 50.0 & 0.001 & 47.8 & 45.3 & 46.6 & 0.800 \\
\hline High alcohol intake pattern ${ }^{f}$ & 21.7 & 16.2 & 10.3 & 0.001 & 14.6 & 15.1 & 13.2 & 0.567 \\
\hline \multicolumn{9}{|l|}{ Hypertension comorbidity } \\
\hline Diabetes $^{9}$ & 43.5 & 41.7 & 36.3 & 0.009 & 42.2 & 44.7 & 36.6 & 0.094 \\
\hline Dyslipidaemia $^{\text {h }}$ & 73.7 & 76.4 & 83.2 & 0.001 & 81.0 & 73.6 & 79.8 & 0.894 \\
\hline \multicolumn{9}{|l|}{ Blood pressure } \\
\hline Optimal control of blood pressure & 26.5 & 33.9 & 36.3 & 0.001 & 31.3 & 41.5 & 34.6 & 0.520 \\
\hline Systolic blood pressure $(\mathrm{mmHg})^{\dagger}$ & 151.1(19.0) & $147.8(18.9)$ & $150.4(18.9)$ & 0.001 & $146.1(17.0)$ & $145.8(18.7)$ & 146.7(18.9) & 0.832 \\
\hline Diastolic blood pressure $(\mathrm{mmHg})^{\dagger}$ & $83.7(10.2)$ & $83.1(10.0)$ & $82.6(9.4)$ & 0.052 & 83.7(9.6) & $83.3(10.4)$ & $82.3(9.6)$ & 0.143 \\
\hline Antihypertensive treatment ${ }^{j}$ & 80.6 & 85.8 & 87.2 & 0.001 & 85.5 & 85.5 & 86.8 & 0.680 \\
\hline
\end{tabular}

${ }^{a}$ Taking at least one of the following drugs: Selective serotonin reuptake inhibitors, non-selective monoamine reuptake inhibitors, Monoamine oxidase A inhibitors, antidepressants in combination with psycholeptics, others antidepressant agents.

${ }^{\mathrm{b}}$ Taking at least one of the following drugs: benzodiazepine derivatives, azaspirodecanedione derivatives, GABA (gamma-aminobutyric acid) analogues, natural antianxiety agents, ethanolamine derivatives, other anxiolytics, hypnotics and sedatives agents.

cCurrent smoker.

${ }^{\mathrm{d}}$ Adherence to Mediterranean diet pattern $<9$ points (median) on a scale of $0-14$.

ePhysical activity in leisure time $<1000 \mathrm{kcal} /$ week in last year.

fAlcohol consumption more than $20 \mathrm{gr}$. daily in men and $10 \mathrm{gr}$. daily in women.

${ }^{9}$ Diagnosis of diabetes.

${ }^{\mathrm{h}}$ Diagnosis of dyslipidaemia.

'Systolic blood pressure $<140 \mathrm{mmHg}$ and diastolic blood pressure $<90 \mathrm{mmHg}$.

'Taking at least one of the following antihypertensive drugs: angiotensin-converting-enzyme inhibitor (ACE inhibitors), diuretics, calcium channel blockers, angiotensin II receptor antagonists, Beta-blockers, a-blockers, or other antihypertensive drugs.

${ }^{\dagger}$ Mean - Standard Deviation, $\mathrm{p}$ - value: ANOVA F test. 
models. An alpha level $<0.05$ and a confidence interval (CI) of $95 \%$ were employed for all statistical analyses. The goodness-of-fit logistic models were performed using Hosmer and Lemeshow test, and for linear model residual validation the Kolmogorov test was used.

\section{Results}

Mean age of the participants was 67.2 years (SD 6.2), $60.5 \%$ were women, and $15.6 \%$ had depression. Amongst this group $71 \%$ had had depression diagnosed more than six years ago.

\section{Bivariate analysis}

\section{Characteristics of participants according to depression}

Depressive participants were more commonly women, had low educational level, presented more obesity, and were sedentary and dyslipidemic. In contrast, members of this group were less frequently smokers and alcohol drinkers. With respect to BP, depressive participants had lower SBP and DBP values (Table 1). Participants with treated depression had a higher percentage of BP control, and a greater probability of receiving antihypertensive treatment. The percentage of patients receiving antidepressants was higher in those diagnosed more recently (less than 5 years).

\section{Control of blood pressure}

After adjusting for the main co-variables (age, sex, antianxiety or sedative treatment, diabetes, dyslipidemia and anti-hypertensive treatment) and potential confounding factors (educational levels, BMI, smoking, diet pattern, and physical activity) depressive participants, with or without antidepressants, more frequently presented wellcontrolled BP than non-depressive ones (OR: 1.28, CI95\%: 1.06-1.55 and OR: 1.30, CI95\%: 1.03-1.65, respectively). Participants whose depression had been previously diagnosed between six and ten years had better BP control than the more recently diagnosed ones (OR: 1.62, CI95\%: 1.07-2.45) (Figure 1). When considering BP as a continuous variable, only SBP figures were significantly lower in depressive patients, whilst DBP ones were unaffected (Table 2). Women, younger participants, and lower BMI were found to be related to better SBP and DBP levels.

\section{Discussion}

In the present study we found that depressive, hypertensive participants at high cardiovascular risk had better $\mathrm{BP}$ values.

Although depression is considered an independent risk factor for hypertension incidence, and a number of authors have found it related to higher BP levels [19-21], its role in the control of BP values remains unclear [22]. Limited data have reported that hypertensive patients taking antidepressants have lower blood pressure levels [23]. One possible explanation for the effect of antidepressants on lowering blood pressure could be a reduction in vagal activity, decreased heart rate variability and baroreflex sensitivity [24], and neuro-endocrine pathways [25-29]. Our results concur with other studies performed in general populations $[12,13,24,30]$. Research analyzing a

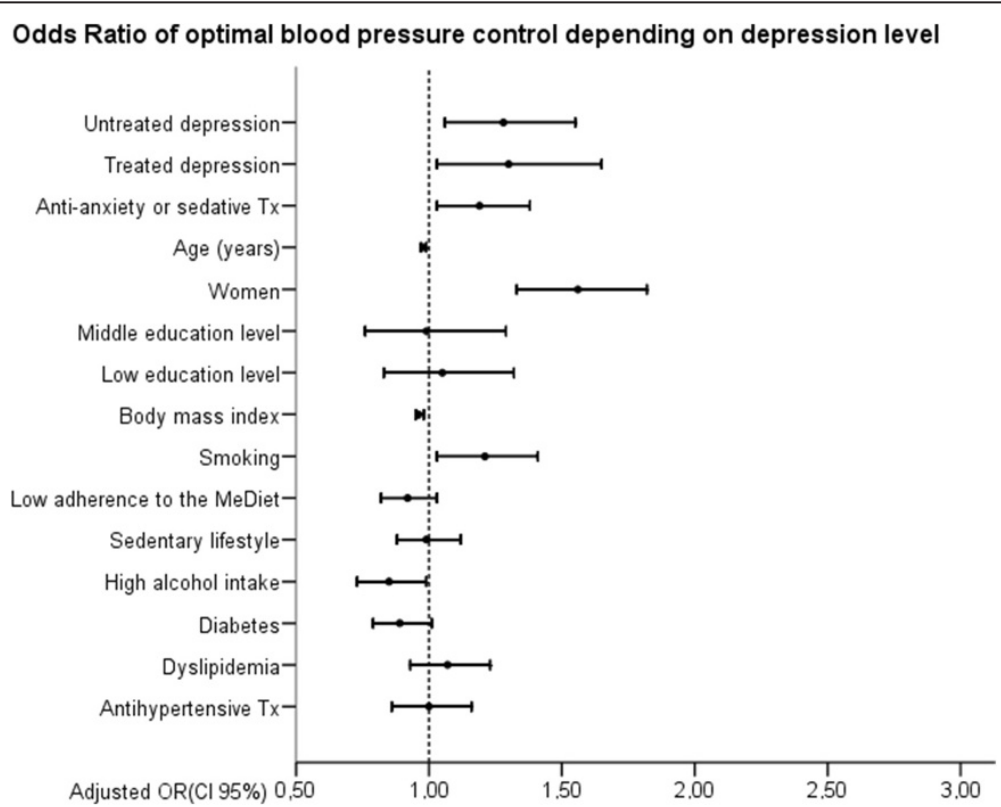

Figure 1 Odds Ratios of optimal blood pressure control according to depression level. Circles represent Odds Ratios, Horizontal lines indicate $95 \%$ confidence intervals and vertical line references $\mathrm{OR}=1$. Tx indicates treatment and MeDiet indicates the Mediterranean Diet. No depression is the reference category for the response variable. 
Table 2 Log-linear model coefficients of systolic and diastolic blood pressure according to depression level and adjusted co-variables

\begin{tabular}{|c|c|c|c|c|c|c|c|c|}
\hline & \multicolumn{4}{|c|}{$\begin{array}{l}\text { Natural logarithm of systolic blood pressure } \\
\qquad(\mathrm{mmHg})^{\dagger}\end{array}$} & \multicolumn{4}{|c|}{$\begin{array}{l}\text { Natural logarithm of diastolic blood pressure } \\
\qquad(\mathrm{mmHg})^{\ddagger}\end{array}$} \\
\hline & Coefficients $^{\S}$ & $\begin{array}{l}\text { Lower } \\
\mathrm{Cl} 95 \%{ }^{\S}\end{array}$ & $\begin{array}{l}\text { Upper } \\
\mathrm{Cl} 95 \%{ }^{\S}\end{array}$ & P-value & Coefficients $^{\S}$ & $\begin{array}{l}\text { Lower } \\
\mathrm{Cl} 95 \%^{\S}\end{array}$ & $\begin{array}{l}\text { Upper } \\
\mathrm{Cl} 95 \%{ }^{\S}\end{array}$ & P-value \\
\hline \multicolumn{9}{|l|}{ Depression level } \\
\hline No Depression & Ref & Ref & Ref & Ref & Ref & Ref & Ref & Ref \\
\hline Untreated depression ${ }^{\mathrm{a}}$ & -1.59 & -2.69 & -0.50 & 0.004 & -0.59 & -1.64 & 0.462 & 0.272 \\
\hline Treated depression ${ }^{b}$ & -3.49 & -4.87 & -2.10 & 0.001 & -0.85 & -2.18 & 0.49 & 0.213 \\
\hline Anti-Anxiety or sedative treatment ${ }^{c}$ & -0.82 & -1.66 & 0.02 & 0.056 & -0.18 & -0.99 & 0.62 & 0.657 \\
\hline Age (years) & 0.25 & 0.20 & 0.31 & 0.001 & -0.37 & -0.42 & $0-.32$ & 0.001 \\
\hline Sex (Women) & -2.60 & -3.46 & -1.75 & 0.001 & -2.62 & -3.44 & -1.79 & 0.001 \\
\hline \multicolumn{9}{|l|}{ Educational attainment } \\
\hline High level & Ref & Ref & Ref & Ref & Ref & Ref & Ref & Ref \\
\hline Middle level & 0.96 & -0.45 & 2.37 & 0.183 & 1.09 & -0.27 & 2.44 & 0.117 \\
\hline Low level & 0.13 & -1.12 & 1.38 & 0.841 & -0.42 & -1.62 & 0.78 & 0.491 \\
\hline Body Mass Index $\left(\mathrm{Kg} / \mathrm{m}^{2}\right)$ & 0.24 & 0.16 & 0.33 & 0.001 & 0.42 & 0.34 & 0.50 & 0.001 \\
\hline Smoking $^{d}$ & -0.80 & -1.65 & 0.05 & 0.064 & -0.76 & -1.57 & 0.05 & 0.067 \\
\hline $\begin{array}{l}\text { Low adherence to the } \\
\text { MeDiet pattern }\end{array}$ & 0.11 & -0.56 & 0.78 & 0.746 & -0.01 & -0.65 & 0.64 & 0.989 \\
\hline Sedentary ${ }^{f}$ & 0.17 & -0.46 & 0.80 & 0.600 & -0.07 & -0.68 & 0.54 & 0.816 \\
\hline High alcohol intake & 0.64 & -0.17 & 1.45 & 0.122 & 0.72 & -0.06 & 1.50 & 0.069 \\
\hline Diabetes $^{\mathrm{h}}$ & 1.28 & 0.62 & 1.94 & 0.001 & -1.94 & -2.57 & -1.30 & 0.001 \\
\hline Dyslipidemia ${ }^{i}$ & -0.34 & -0.34 & 0.41 & 0.370 & -0.60 & -1.31 & 0.12 & 0.104 \\
\hline Antihypertensive treatment $^{j}$ & 0.55 & -0.26 & 1.37 & 0.182 & 0.46 & -0.32 & 1.24 & 0.252 \\
\hline
\end{tabular}

${ }^{a}$ Diagnosis of depression and not taking any antidepressant drugs.

${ }^{b}$ Diagnosis of depression and taking at least one of the following drugs: Selective serotonin reuptake inhibitors, non-selective monoamine reuptake inhibitors,

Monoamine oxidase A inhibitors, antidepressants in combination with psycholeptics, others antidepressant agents.

'Taking at least one of the following drugs: benzodiazepine derivatives, azaspirodecanedione derivatives, GABA (gamma-aminobutyric acid) analogues, natural

antianxiety agents, ethanolamine derivatives, other anxiolytics, hypnotics and sedatives agents.

${ }^{\mathrm{d}}$ Current smoker.

${ }^{\mathrm{e}}$ Adherence to Mediterranean diet pattern $<9$ points (median) on a scale of 0-14.

fPhysical activity in leisure time $<1000 \mathrm{kcal} /$ week in last year.

${ }^{g}$ Alcohol consumption more than $20 \mathrm{gr}$. daily in men and $10 \mathrm{gr}$. daily in women.

h'Diagnosis of diabetes.

'Diagnosis of dyslipidaemia.

'Taking at least one of the following antihypertensive drugs: angiotensin-converting-enzyme inhibitor (ACE inhibitors), diuretics, calcium channel blockers, angiotensin II receptor antagonists, Beta-blockers, a-blockers, or other antihypertensive drugs.

${ }^{\dagger}$ Kolmogorov-Smirnov Test ( $p$ value): 0.271.

${ }^{\ddagger}$ Kolmogorov-Smirnov Test ( $p$ value): 0.56 .

${ }^{\S}$ Coefficients values multiplied by 100 .

group of people with hypertension who were taking antihypertensive drugs has also shown that individuals with episodes, or symptoms of depression, tended to have lower SBP and DBP [31]. It is not clear whether depression is the cause or the consequence of differences in the control of BP values [32,33]. Confounders related to both hypertension and depression, such as physical activity, low-fat diet, non-smoking, and alcohol intake, were included in our analysis [34]. Some antidepressant, anti-anxiety, and antipsychotic agents, either alone or in combination with cardiovascular therapies including antihypertensive drugs, have been reported to induce a drop in BP [35-37]. Our participants diagnosed with depression, and those taking antidepressant treatments, received more antihypertensive drugs. Nevertheless, the association observed between depression and better blood pressure values persisted after adjusting for this variable in the multivariate analysis, which indicates that this association may be independent, as has been shown in previous studies $[24,33]$.

It could be hypothesized, moreover, that the frequent use of health services by depressive patients could contribute to an accurate follow-up and good control of their hypertension. The Spanish Health System guarantees a 
free and universal access to primary healthcare services. In addition, family doctors have access to well-established chronic care protocols, which ensure the better control and follow-up of patients with co-morbidity (hypertension and depression).

\section{Implication of our results}

Our findings indicate the relevance of performing a holistic approach to the co-morbidity when tackling the care of chronic patients attended in primary care. Preventions among family physicians toward the use of antidepressants in hypertensive patients with depression should be addressed individually since many studies have shown an improvement in BP control.

\section{Study limitations and strengths}

The cross-sectional design of our study does not allow causal inferences to be drawn. Future observational research studies are needed to establish the role of psychosocial factors in the good control of cardiovascular risk factors and the prognosis of cardiovascular diseases, especially in hypertensive individuals or those at high cardiovascular risk.

For reasons of statistical power the different antidepressants were grouped together. It is possible that a larger sample could establish variations according to the antidepressant analyzed. The time elapsed from the first diagnosis of depression could not be used as a proxy for the current prevalence of depression as the only way to establish the current state of the disease is through the prescription of antidepressants, and no specific tests were conducted in the participants. We had information about the family history of cardiovascular diseases history but none concerning about family history of depression and hypertension.

\section{Conclusion}

Among hypertensive patients at high cardiovascular risk, blood pressure was better controlled in those diagnosed with depression.

\footnotetext{
Abbreviations

CVD: Cardiovascular diseases; BP: Blood pressure; BMI: Body mass index: SBP: Diastolic blood pressure; DBP: Diastolic blood pressure; SD: Standard deviation; OR: Odds ratio; Cl: Confidence interval.
}

\section{Competing interests}

Dr. Estruch reports serving on the board of and receiving lecture fees from the Research Foundation on Wine and Nutrition (FIVIN), serving on the boards of the Beer and Health Foundation and the European Foundation for Alcohol Research (ERAB), receiving lecture fees from Cerveceros de España and Sanofi-Aventis, and receiving grant support through his institution from Novartis. Dr.Salas-Salvadó reports serving on the board of and receiving grant support through his institution from the International Nut and Dried Fruit Council, receiving consulting fees from Danone, and receiving grant support through his institution from Eroski and Nestlé. Dr. Arós reports receiving payment for the development of educational presentations from Menarini and AstraZeneca. Dr. Serra-Majem reports serving on the boards of the Mediterranean Diet Foundation and the Beer and Health Foundation. Dr. Pintó reports serving on the board of and receiving grant support through his institution from the Residual Risk Reduction Initiative (R3i) Foundation, serving on the board of Omegafort, serving on the board of and receiving payment for the development of educational presentations, as well as grant support through his institution, from Ferrer, receiving consulting fees from Abbott Laboratories, receiving lecture fees, as well as grant support through his institution, from Merck and Roche receiving lecture fees from Danone and Esteve, receiving payment for the development of educational presentations from Menarini, and receiving grant support through his institution from Sanof i-Aventis, Kowa, Unilever, Boehringer Ingelheim, and Karo Bio. No other potential conflict of interest relevant to this article was reported.

\section{Authors' contributions}

$C M-L$ and MAM. conceived and designed the study. They also analyzed and interpreted the study data, and wrote the first draft of the manuscript. RE, MAM-G., JS.-S, DC, EG-G, M.F, JL, M.Fitó, FA, LS.-M, XP., JB, JVS, assisted in the acquisition of data and provided valuable, intellectual contributions to the manuscript draft. All authors have approval the final version submitted for publication.

\section{Authors' information}

This work has been carried out within the framework of the Predimed Study, one of the largest clinical trials ever performed to date regarding the association of a Mediterranean Intervention on cardiovascular morbi-mortality. The network consisted of more than seventeen different multidisciplinary research groups including experts on nutrition and internal medicine, cardiologists, and family physicians.

The main outcomes of the study were published last year [14].

\section{Funding}

This study was supported by the official funding agency for biomedical research of the Spanish government, Instituto de Salud Carlos III (ISCIII), through grants provided to research networks specifically developed for the trial (RTIC G03/140, RTIC RD 06/0045) and through Centro de Investigación Biomédica en Red de Fisiopatología de la Obesidad y Nutrición [CIBERobn]), and by grants from Centro Nacional de Investigaciones Cardiovasculares (CNIC 06/2007), Fondo de Investigación Sanitaria-Fondo Europeo de Desarrollo Regional (PI04-2239, PI 05/2584, CP06/00100, PI07/0240, PI07/1138, Pl07/0954, Pl 07/0473, Pl10/01407, Pl10/02658, Pl11/01647, and P11/02505), Ministerio de Ciencia e Innovación (AGL-200913906-C02 and AGL2010-22319-C03), Fundación Mapfre 2010, Consejería de Salud de la Junta de Andalucía (PI0105/2007), Public Health Division of the Department of Health of the Autonomous Government of Catalonia, Generalitat Valenciana (ACOMP06109, GVACOMP2010-181, GVACOMP2011-151, CS2010AP-111,CS2011-AP-042), and Regional Government of Navarra (P27/2011). None of the institutions described above have influenced the design, collection, analysis, and interpretation of data; the writing of the manuscript; and the decision to submit the manuscript for publication.

\section{Author details}

'Department of Paediatrics, Obstetrics, Gynaecology and Preventive Medicine, Universitat Autònoma de Barcelona, Barcelona, Spain. ${ }^{2}$ Centro de Investigación Biomédica en Red de Fisiopatología de la Obesidad y Nutrición (ClBERobn), Instituto de Salud Carlos III, Madrid, Spain. ${ }^{3}$ The PREDIMED Study (Prevención con Dieta Mediterránea) Network (RD 06/0045), Instituto de Salud Carlos III, Madrid, Spain. ${ }^{4}$ The Department of Internal Medicine of Hospital Clinic, Institut d'Investigacions Biomèdiques August Pi I Sunyer, University of Barcelona, Barcelona, Spain. ${ }^{5}$ Preventive Medicine and Public Health, University of Navarra, Pamplona, Spain. ${ }^{6}$ Human Nutrition Department, Hospital Universitari Sant Joan, Institut d'Investigació Sanitaria Pere Virgili, Universitat Rovira i Virgili, Reus, Spain. ${ }^{7}$ The Department of Preventive Medicine, University of Valencia, Valencia, Spain. ${ }^{8}$ The Department of Preventive Medicine, University of Malaga, Malaga, Spain. Institute of Health Sciences (IUNICS), University of Balearic Islands, and Hospital Son Espases, Palma de Mallorca, Spain. ${ }^{10}$ The Department of Family Medicine, Primary Care Division of Seville, San Pablo Health Center, Seville, Spain. ${ }^{11}$ Cardiovascular Risk and Nutrition Research Group of Institut Mar d'Investigacions Mèdiques (IMIM)-Research Institute Hospital del Mar, 
Barcelona, Spain. ${ }^{12}$ The Department of Cardiology, University Hospital of Alava, Vitoria, Spain. ${ }^{13}$ The Department of Clinical Sciences, University of Las Palmas de Gran Canaria, Las Palmas, Spain. ${ }^{14}$ Lipids and Vascular Risk Unit, Internal Medicine, Hospital Universitario de Bellvitge, Hospitalet de Llobregat, Barcelona, Spain. ${ }^{15}$ Primary Care Division, Catalan Institute of Health, Institut d'Investigació en Atenció Primària Jordi Gol, Tarragona-Reus, Spain. ${ }^{16}$ Primary Care Division, Valencia Institute of Health, Valencia, Spain. ${ }^{17}$ Catalan Institute of Health, Institut d'Investigació en Atenció Primària Jordi Gol, Sardenya 375, Entlo, 08025 Barcelona, Spain.

Received: 9 April 2014 Accepted: 20 August 2014

Published: 26 August 2014

\section{References}

1. Global Health Observatory (GHO), World Health Organization: Raised blood pressure: Situation and trends. [http://www.who.int/gho/ncd/risk_factors/ blood_pressure prevalence text/en/]

2. Institute for Health Metrics and Evaluation: The Global Burden of Disease: Generating Evidence, Guiding Policy. Seattle: WA, IHM; 2013.

3. Perk J, De Backer G, Gohlke H, Graham I, Reiner Z, Verschuren WM, Albus C, Benlian P, Boysen G, Cifkova R, Deaton C, Ebrahim S, Fisher M, Germano G, Hobbs R, Hoes A, Karadeniz S, Mezzani A, Prescott E, Ryden L, Scherer M, Syvänne M, Scholte Op Reimer WJ, Vrints C, Wood D, Zamorano JL, Zannad F, Fifth Joint Task Force of the European Society of Cardiology and Other Societies on Cardiovascular Disease Prevention in Clinical Practice; European Association for Cardiovascular Prevention and Rehabilitation: European Guidelines on cardiovascular disease prevention in clinical practice (version 2012). The Fifth Joint Task Force of the European Society of Cardiology and Other Societies on Cardiovascular Disease Prevention in Clinical Practice (constituted by representatives of nine societies and by invited experts). Eur Heart J 2012, 33:1635-1701.

4. Go AS, Mozaffarian D, Roger VL, Benjamin EJ, Berry JD, Borden WB, Bravata DM, Dai S, Ford ES, Fox CS, Franco S, Fullerton HJ, Gillespie C, Hailpern SM, Heit JA, Howard VJ, Huffman MD, Kissela BM, Kittner SJ, Lackland DT, Lichtman JH, Lisabeth LD, Magid D, Marcus GM, Marelli A, Matchar DB, McGuire DK, Mohler ER, Moy CS, Mussolino ME, et al: Heart disease and stroke statistics-2013 update: a report from the American Heart Association. Circulation 2013, 127:e6-e245.

5. Hemingway $\mathrm{H}$, Marmot M: Evidence based cardiology: psychosocial factors in the aetiology and prognosis of coronary heart disease. Systematic review of prospective cohort studies. BMJ 1999 318:1460-1467.

6. Rozanski A, Blumenthal JA, Davidson KW, Saab PG, Kubzansky L: The epidemiology, pathophysiology, and management of psychosocial risk factors in cardiac practice: the emerging field of behavioral cardiology. J Am Coll Cardiol 2005, 45:637-651.

7. Yusuf S, Hawken S, Ounpuu S, Dans T, Avezum A, Lanas F, McQueen M, Budaj A, Pais P, Varigos J, Lisheng L, INTERHEART Study Investigators: Effect of potentially modifiable risk factors associated with myocardial infarction in 52 countries (the INTERHEART study): case-control study. Lancet 2004, 364:937-952.

8. World Health Organization: Depression. Fact sheet N 369. [http://www.who. int/mediacentre/factsheets/fs369/en/

9. Rutledge T, Hogan BE: A quantitative review of prospective evidence linking psychological factors with hypertension development. Psychosom Med 2002, 64:758-766.

10. Elderon L, Whooley MA: Depression and cardiovascular disease. Prog Cardiovasc Dis 2013, 55:511-523.

11. Scalco AZ, Scalco MZ, Azul JB, Lotufo NF: Hypertension and depression. Clinics (Sao Paulo) 2005, 60:241-250

12. Delaney JA, Oddson BE, Kramer H, Shea S, Psaty BM, McClelland RL: Baseline depressive symptoms are not associated with clinically important levels of incident hypertension during two years of follow-up: the multi-ethnic study of atherosclerosis. Hypertension 2010, 55:408-414

13. Licht CM, de Geus EJ, Seldenrijk A, van Hout HP, Zitman FG, van Dyck R, Penninx BW: Depression is associated with decreased blood pressure, but antidepressant use increases the risk for hypertension. Hypertension 2009, 53:631-638.

14. Martínez-González MÁ, Corella D, Salas-Salvadó J, Ros E, Covas MI, Fiol M, Wärnberg J, Arós F, Ruíz-Gutiérrez V, Lamuela-Raventós RM, Lapetra J,
Muñoz MÁ, Martínez JA, Sáez G, Serra-Majem L, Pintó X, Mitjavila MT, Tur $J A$, Portillo MP, Estruch R, PREDIMED Study Investigators: Cohort profile: design and methods of the PREDIMED study. Int J Epidemiol 2012, 41:377-385.

15. Estruch R, Ros E, Salas-Salvado J, Covas MI, Corella D, Arós F, GómezGracia E, Ruiz-Gutiérrez V, Fiol M, Lapetra J, Lamuela-Raventos RM, Serra-Majem L, Pintó X, Basora J, Muñoz MA, Sorlí JV, Martínez JA, Martínez-González MA, PREDIMED Study Investigators: Primary prevention of cardiovascular disease with a Mediterranean diet. N Engl J Med 2013, 368:1279-1290.

16. Martinez-Gonzalez MA, Fernandez-Jarne E, Serrano-Martinez M, Wright M, Gomez-Gracia E: Development of a short dietary intake questionnaire for the quantitative estimation of adherence to a cardioprotective Mediterranean diet. Eur J Clin Nutr 2004, 58:1550-1552.

17. Elosua R, Marrugat J, Molina L, Pons S, Pujol E: Validation of the Minnesota Leisure Time Physical Activity Questionnaire in Spanish men. The MARATHOM Investigators. Am J Epidemiol 1994, 139:1197-1209

18. Elosua R, Garcia M, Aguilar A, Molina L, Covas MI, Marrugat J: Validation of the Minnesota Leisure Time Physical Activity Questionnaire In Spanish Women. Investigators of the MARATDON Group. Med Sci Sports Exerc 2000, 32:1431-1437.

19. Shinagawa M, Otsuka K, Murakami S, Kubo Y, Cornelissen G, Matsubayashi K, Yano S, Mitsutake G, Yasaka K, Halberg F: Seven-day (24-h) ambulatory blood pressure monitoring, self-reported depression and quality of life scores. Blood Press Monit 2002, 7:69-76.

20. Nabi H, Chastang JF, Lefèvre T, Dugravot A, Melchior M, Marmot MG Shipley MJ, Kivimäki M, Singh-Manoux A: Trajectories of depressive episodes and hypertension over 24 years: the Whitehall II prospective cohort study. Hypertension 2011, 57:710-716.

21. Kabir AA, Whelton PK, Khan MM, Gustat J, Chen W: Association of symptoms of depression and obesity with hypertension: the Bogalusa Heart Study. Am J Hypertens 2006, 19:639-645.

22. Meng $L$, Chen D, Yang $Y$, Zheng $Y$, Hui R: Depression increases the risk of hypertension incidence: a meta-analysis of prospective cohort studies. J Hypertens 2012, 30:842-851.

23. Dawood T, Lambert EA, Barton DA, Laude D, Elghozi JL, Esler MD, Haikerwal D, Kaye DM, Hotchkin EJ, Lambert GW: Specific serotonin reuptake inhibition in major depressive disorder adversely affects novel markers of cardiac risk. Hypertens Res 2007, 30:285-293.

24. Kim BS, Bae JN, Cho MJ: Depressive symptoms in elderly adults with hypotension: different associations with positive and negative affect. J Affect Disord 2010, 127:359-364.

25. Joynt KE, Whellan DJ, O'Connor CM: Depression and cardiovascular disease: mechanisms of interaction. Biol Psychiatry 2003, 54:248-261.

26. Huffman JC, Celano CM, Beach SR, Motiwala SR, Januzzi JL: Depression and cardiac disease: epidemiology, mechanisms, and diagnosis. Cardiovasc Psychiatry Neurol 2013, 2013:695925

27. Pozuelo L, Tesar G, Zhang J, Penn M, Franco K, Jiang W: Depression and heart disease: what do we know, and where are we headed? Cleve Clin $J$ Med 2009, 76:59-70.

28. Grippo AJ, Johnson AK: Stress, depression and cardiovascular dysregulation: a review of neurobiological mechanisms and the integration of research from preclinical disease models. Stress 2009, 12:1-21.

29. Perlmuter LC, Sarda G, Casavant V, O'Hara K, Hindes M, Knott PT, Mosnaim AD: A review of orthostatic blood pressure regulation and its association with mood and cognition. Clin Auton Res 2012, 22:99.

30. Hildrum B, Ulla R, Holmen J: Anxiety and depression lower blood pressure: 22-year follow-up of the population based HUNT study. Norway. BMC Public Health 2011, 11:601.

31. Lenoir $H$, Lacombe JM, Dufouil C, Ducimetière $P$, Hanon $O$, Ritchie $K$ Dartiques JF, Alpérovitch A, Tzourio C: Relationship between blood pressure and depression in the elderly. The Three-City Study. J Hypertens 2008, 26:1765-1772.

32. Stroup-Benham CA, Markides KS, Black SA, Goodwin JS: Relationship between low blood pressure and depressive symptomatology in older people. J Am Geriatr Soc 2000, 48:250-255.

33. Barrett-Connor E, Palinkas LA: Low blood pressure and depression in older men: a population based study. BMJ 1994, 308:446-449.

34. Dickey RA, Janick JJ: Lifestyle modifications in the prevention and treatment of hypertension. Endocr Pract 2001, 7:392-399. 
35. Januzzi JL Jr, Stern TA, Pasternak RC, DeSanctis RW: The influence of anxiety and depression on outcomes of patients with coronary artery disease. Arch Intern Med 2000, 160:1913-1921.

36. Hill KD, Wee R: Psychotropic drug-induced falls in older people: a review of interventions aimed at reducing the problem. Drugs Aging 2012, 29:15-30.

37. Tyberghein M, Philips JC, Krzesinski JM, Scheen AJ: Orthostatic hypotension: definition, symptoms, assessment and pathophysiology. Rev Med Liege 2013, 68:65-73.

doi:10.1186/1471-2261-14-109

Cite this article as: Mejia-Lancheros et al:: Blood pressure values and depression in hypertensive individuals at high cardiovascular risk. BMC Cardiovascular Disorders 2014 14:109.

\section{Submit your next manuscript to BioMed Central and take full advantage of:}

- Convenient online submission

- Thorough peer review

- No space constraints or color figure charges

- Immediate publication on acceptance

- Inclusion in PubMed, CAS, Scopus and Google Scholar

- Research which is freely available for redistribution 